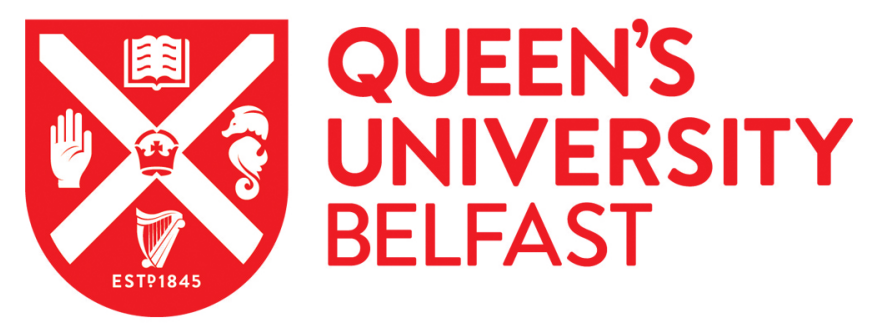

\title{
A comparison of different pre-lysis methods and extraction kits for recovery of Stretococcus agalacticae (Lancefield group B Streptococcus) DNA from whole blood
}

Burke, R. M., McKenna, J. P., Cox, C., Coyle, P. V., Shields, M. D., \& Fairley, D. J. (2016). A comparison of different pre-lysis methods and extraction kits for recovery of Stretococcus agalacticae (Lancefield group B Streptococcus) DNA from whole blood. Journal of Microbiological Methods, 129, 103-108.

https://doi.org/10.1016/j.mimet.2016.08.016

\section{Published in:}

Journal of Microbiological Methods

\section{Document Version:}

Peer reviewed version

Queen's University Belfast - Research Portal:

Link to publication record in Queen's University Belfast Research Portal

\section{Publisher rights}

(c) 2016 Elsevier Ltd. This manuscript version is made available under the CC-BY-NC-ND 4.0 license http://creativecommons.org/licenses/by$\mathrm{nc}-\mathrm{nd} / 4.0 /$ which permits distribution and reproduction for non-commercial purposes, provided the author and source are cited.

\section{General rights}

Copyright for the publications made accessible via the Queen's University Belfast Research Portal is retained by the author(s) and / or other copyright owners and it is a condition of accessing these publications that users recognise and abide by the legal requirements associated with these rights.

Take down policy

The Research Portal is Queen's institutional repository that provides access to Queen's research output. Every effort has been made to ensure that content in the Research Portal does not infringe any person's rights, or applicable UK laws. If you discover content in the

Research Portal that you believe breaches copyright or violates any law, please contact openaccess@qub.ac.uk. 
1 A comparison of different pre-lysis methods and extraction kits for recovery of Streptococcus

2 agalacticae (Lancefield group B Streptococcus) DNA from whole blood.

3

4 Rachael M. Burke, ${ }^{\mathrm{a}, \mathrm{b}}$ James P. McKenna, ${ }^{\mathrm{b}}$ Ciara Cox, ${ }^{\mathrm{b}}$ Peter V. Coyle, ${ }^{\mathrm{b}}$ Michael D. Shields, ${ }^{\mathrm{a}, \mathrm{c}}$ Derek

5 J. Fairley ${ }^{\mathrm{a}, \mathrm{b}} \#$

6

7 Centre for Infection and Immunity, Queens University Belfast, Northern Ireland ${ }^{a}$; Regional Virus

8 Laboratory / Department of Microbiology, Belfast Health and Social Care Trust, Northern Ireland ${ }^{\mathrm{b}}$;

9 Royal Belfast Hospital for Sick Children, Northern Ireland ${ }^{\mathrm{c}}$

11 Running head: S. agalactiae DNA recovery from blood

12

13 \# Address correspondence to Derek J. Fairley, derek.fairley@belfasttrust.hscni.net

14

15

16

17

18

19

20

21

22

23

24 
ABSTRACT

Streptococcus agalactiae (Lancefield Group B streptococcus [GBS]) is the most common cause of serious bacterial illness in neonates. Incidence of GBS disease in neonates less than 90 days old is 0.43 per 1000 births, with a case fatality of $12 \%$ (1). Conventional detection of GBS from patient samples using culture is both time-consuming and unreliable, particularly if samples are taken after antibiotics are administered (2). Laboratory diagnosis involves culture of recto-vaginal swab samples (when screening for antepartum or intrapartum carriage) and culture of blood and/or cerebrospinal fluid (CSF) samples from unwell neonates or neonates known to have been exposed to maternal GBS (3). Effective molecular tests for GBS would be valuable to clinicians by obviating the need for 
several days of culture. Several quantitative real-time polymerase chain reaction (PCR) assays for GBS have been developed and validated, most for use on vaginal swab samples rather than whole blood (4-7). One recent study showed a real-time PCR assay to detect the cylB gene in blood and/or CSF was significantly more sensitive than culture for diagnosis of GBS infection in neonates (2).

Effective DNA extraction from clinical specimens is critical for molecular pathogen detection. This is particularly the case for whole blood, where the complex matrix and presence of PCR inhibitors can make DNA extraction difficult $(8,9)$. It is well established that different methods of sample preparation and DNA extraction have a significant impact on overall assay sensitivity $(10,11)$. GBS is a Gram-positive organism with a robust cell wall, and accordingly it can be difficult to lyse bacterial cells to release genomic DNA (9). This makes molecular detection of GBS much more challenging than, for example, Neisseria meningitidis (an easily-lysed Gram-negative organism) where PCR testing is widely recognised as a gold standard method $(12,13)$.

Molecular testing of neonatal blood and/or CSF specimens may improve the diagnosis of early-onset sepsis caused by GBS, as detection of GBS DNA in a sterile site specimen would confirm the diagnosis. However, failure to lyse GBS cells will adversely affect detection limits and clinical sensitivity of molecular GBS tests. This study aimed to optimise extraction of GBS DNA from whole blood, and to improve detection limits for molecular GBS detection. We report data from three different pre-lysis methods and five different DNA extraction kits on the yield of GBS DNA from spiked samples of saline and whole blood. Significant differences in yield were observed using different extraction methods, with exceptionally low yields seen when commonly used extraction kits were used without pre-lysis. 


\section{METHODS}

\section{Preparation of GBS-spiked samples}

Streptococcus agalactiae (strain ATCC 12386) was cultured overnight on Columbia Blood Agar (CBA) at $37^{\circ} \mathrm{C}$ in a $10 \% \mathrm{CO}_{2}$ atmosphere and resuspended in sterile phosphate buffered saline (PBS) to an optical density of $\sim 1.5$. Tenfold serial dilutions were prepared with the number of colony forming units per ml (CFU.ml ${ }^{-1}$ ) ascertained by the spread plate method (14). Triplicate aliquots (100 $\mu$ l) of duplicate serial dilutions were plated onto CBA plates. Following overnight incubation at $37^{\circ} \mathrm{C}$ in $10 \%$ $\mathrm{CO}_{2}$ atmosphere individual colonies were counted and the mean CFU.ml ${ }^{-1}$ count determined. Aliquots $(200 \mu \mathrm{l})$ of the GBS suspension were stored at $-20^{\circ} \mathrm{C}$ until required. Each aliquot of GBS cells underwent one freeze-thaw cycle only. Aliquots $(2.8 \mathrm{ml})$ of sterile PBS or whole EDTA-treated human blood were inoculated with cell suspension $(200 \mu \mathrm{l})$ containing either $6.3 \times 10^{4} \mathrm{cfu}^{\mu \mathrm{l}^{-1}}$ ("high spike" sample) or 63 cfu. $\mu \mathrm{l}^{-1}$ (“low spike” sample) prior to DNA extraction.

\section{Sample pre-lysis protocols}

Two protocols for sample pre-lysis prior to DNA extraction were compared: enzymatic lysis using achromopeptidase (ACH, lysyl endopeptidase, EC 3.4.21.50) and mechanical lysis using bead-beating. Controls were extracted without any pre-lysis.

For enzymatic lysis, ACH (100kU; Sigma-Aldrich, Gillingham, U.K.) was dissolved in 5.2ml of TrisEDTA buffer (10mM Tris-HCl, 1mM EDTA, pH 8.0). Sample aliquots (200 $\mu \mathrm{l})$ were mixed with an equal volume of $\mathrm{ACH}$ stock $(200 \mu \mathrm{l}$, containing $3.85 \mathrm{kU} \mathrm{ACH})$ and incubated at room temperature $\left(22^{\circ} \mathrm{C}\right)$ for 5 minutes. For spiked saline samples, $\mathrm{ACH}$ was inactivated prior to extraction by heating to $95^{\circ} \mathrm{C}$ for 5 minutes. Preliminary experiments found the efficiency of ACH lysis in EDTA-blood was significantly reduced compared to lysis in saline (data not shown). Dilution (1:4) with Tris-HCl buffer 
(10mM, pH 8.0) prior to ACH treatment resolved this, so blood samples were diluted before addition of ACH and incubation. For blood samples, instead of heating (which caused blood to clot), ACH was inactivated prior to extraction by addition of lysis buffer from the extraction kit being evaluated.

For mechanical lysis, samples were processed by bead-beating using Pathogen Lysis Tubes S (Qiagen, Manchester, UK). Saline or blood $(400 \mu \mathrm{l})$ spiked with GBS cells were mixed with lysis buffer $(100 \mu \mathrm{L})$ containing anti-foam Reagent DX (0.67\% v/v) in a Lysis Tube. The recommended lysis buffer for each extraction protocol being evaluated was used (Qiagen Buffer ATL, Fuji Buffer LDB or Roche Lysis Buffer). Bead beating was done using a Mini-BeadBeater-1 (Biospec Products Inc., Bartlesville, USA) on full speed for 90 seconds.

\section{DNA extraction protocols}

Following sample pre-lysis, five different DNA extraction kits were compared (Table 1): QIAamp Blood Mini kit (Qiagen); QIAamp UCP Pathogen Mini kit (Qiagen); QuickGene DNA Whole Blood kit S (Fuji); MagNA Pure Compact Nucleic Acid Isolation Kit I (Roche Diagnostics Corp., Indianaopolis, US); and SpeedXtract Nucleic Acid Kit 200 (Qiagen). Each kit was used according to the manufacturers' instructions, with one exception. The SpeedXtract kit uses two rounds of binding onto magnetic beads, leaving the target DNA in solution after the second magnetic separation. The protocol was modified to include ACH pre-lysis between the two magnetic separations, prior to removal of the magnetic beads. Buffer EN $(400 \mu 1)$ was added to spiked EDTA whole blood $(200 \mu l)$ and incubated with SpeedXtract Suspension A magnetic beads, according to the manufacturer's protocol for liquid samples. Following magnetic separation, removal of supernatant and a wash step using Buffer EN, the Suspension A beads were resuspended in ACH $(100 \mu l)$ and incubated at room temperature for 5 minutes followed by heating to $95^{\circ} \mathrm{C}$ for 5 minutes. After $\mathrm{ACH}$ treatment, Buffer SL $(100 \mu \mathrm{l})$ was added and samples were heated again to $95^{\circ} \mathrm{C}$ for 5 minutes before completing the manufacturer's protocol. Controls were extracted without ACH by resuspending the Suspension A 
magnetic beads in Buffer SL $(200 \mu \mathrm{l})$ and heating to $95^{\circ} \mathrm{C}$ for 10 minutes. It was not feasible to incorporate bead-beating into the SpeedXtract protocol without major deviation from the manufacturer's protocol. Bead-beating would either lyse bacterial cells in blood prior to the first magnetic separation (with loss of the bacterial DNA) or would require bead-beating of the magnetic particles prior to the second magnetic separation (with possible mechanical breakdown of the particles).

The QIAamp UCP Pathogen kit was not evaluated without pre-lysis or using ACH pre-lysis, as the manufacturer's protocol specifies bead-beating. Conversely, bead-beating was not evaluated for the QIAamp Blood Mini kit because the extraction chemistry is identical to the QIAamp UCP Pathogen kit. Data from these two kits were therefore combined as a single “Qiagen column” method for comparison with other methods. For both QIAamp kits, extraction columns were processed by centrifugation, according to the manufacturer's instructions. For Fuji and Roche methods, the QuickGene Mini-80 and MagNA Pure Compact systems were used respectively. Following extraction, purified DNA was eluted using the manufacturers' elution buffer for each kit. Elution volume was $100 \mu 1$ for all methods, except SpeedXtract where $200 \mu 1$ elution was used. Combinations of different sample pre-lysis and extraction methods introduced different overall dilution factors (Table S1), so appropriate corrections were required for calculation of yield.

\section{Reference DNA extraction and quantification}

Genomic DNA was extracted from a suspension of S. agalactiae ATCC 12386 in PBS, using the Roche MagNA Pure method with pre-lysis using both ACH and bead-beating. DNA concentration was determined using a NanoDrop ${ }^{\mathrm{TM}} 2000$ UV spectrophotometer (ThermoFisher Scientific Inc., Waltham, USA) and genome copy number per $\mu$ calculated assuming a genome size of $2.13 \times 10^{6}$ bp (S. agalactiae A909 whole genome; RefSeq NC_007432). Calibrators for qPCR were prepared by dilution of the reference DNA stock in Tris-HCl buffer $(1 \mathrm{mM}, \mathrm{pH} 8.0)$ containing $0.1 \mu \mathrm{g} . \mu \mathrm{l}^{-1}$ yeast tRNA 
160 (Sigma-Aldrich, Gillingham, U.K.). Ten-fold serial dilutions over a 6 log range were prepared for 161 qPCR calibration and to evaluate limits of detection.

\section{Real-time quantitative PCR (qPCR)}

A previously published Taqman ${ }^{\circledR}$ qPCR assay targeting the sip gene was used to detect and quantify GBS DNA (7). Primers and probe were synthesised by Eurogentec (Eurogentec, Liège Belgium). The probe was labelled with 5'-FAM and 3'-Black Hole Quencher 1. The final qPCR reaction mix contained 1X Platinum ${ }^{\circledR}$ UDG Mastermix (Thermo Scientific, Manchester, UK), 0.2 $\mu$ M Bovine serum albumin (Sigma, Dorset, UK), 4 mmol.L ${ }^{-1} \mathrm{MgCl}_{2}, 0.4 \mu \mathrm{M}$ forward and reverse primers, $0.2 \mu \mathrm{M}$ probe, Nuclease Free Water (Promega, Southampton, UK) and 3 $\mu$ l of target template for a final reaction volume of $12 \mu \mathrm{l}$. qPCR was performed using a Light Cycler 480 (LC480) instrument (Roche Diagnostics, Mannheim, Germany) using the following thermal cycling program: $95^{\circ} \mathrm{C}$ (10 minutes) followed by 45 cycles of $95^{\circ} \mathrm{C}$ ( 10 seconds) / $60^{\circ} \mathrm{C}$ ( 1 minute), with fluorescence acquisition at the end of each extension cycle. Data were analysed using LC480 software and GBS genome copy number for positive specimens determined from crossing point threshold (Cp) relative to an external calibration curve, prepared as described above, with triplicate assays run on duplicate dilution series. Calibrators and no-template (water) controls were also run with each batch of qPCR samples. PCR efficiency (\% efficiency $\left.=\left[10^{(-1 / \text { slope })}-1\right] \times 100\right)$ and linearity were evaluated by linear regression of log-transformed calibration data. Data were analysed in Excel 2011 (Microsoft Corp., Seattle, USA) and Stata 11 (Stata Corp., Texas, USA).

Data from the "high spike" samples are presented for numerical comparisons of yield, with 95\% confidence intervals (95\% CI), whereas data from the "low spike" samples served to delineate the lower limits of detection. Numerical comparison of yield for the "low spike" samples was not feasible because the yield for many of the methods was so low that many (or all) replicates were negative for 


\section{Performance of qPCR assay}

Efficiency of the sip gene qPCR, calculated from calibrator dilutions over a 6 log range (from 35 genome copies to $3.5 \times 10^{6}$ genome copies per reaction) was $100.3 \%$ with very high linearity $\left(\mathrm{R}^{2}=\right.$ 0.999), indicating the assay had excellent dynamic performance. The lower limit of detection for the assay was found to be 7 genome copies per reaction, as 5/5 replicate assays were positive at that level of dilution. Copy numbers below 7 per reaction were not evaluated.

\section{Reference DNA extraction method}

The highest yields of genomic DNA were obtained by using combined ACH and mechanical pre-lysis of stock GBS suspensions in PBS, followed by MagNA Pure extraction. Genome copy numbers recovered from PBS using this method were 5.5× higher than expected copy numbers calculated from viable count (cfu/ml) data for the GBS spike. This was presumably due to the presence of non-viable and non-culturable cells and chains of GBS cells in the spiked samples, making culture-based estimates of copy number inaccurate. The analytical performance of the qPCR assay meant reliable estimates of genome copy number could be obtained, but only post-extraction. These estimates probably still underestimate the actual genome copy number in the spike, as the yield of the reference extraction method is unlikely to be $100 \%$. The yields of genomic DNA using other extraction methods (each quantified using qPCR, as absolute genome copy numbers) were calculated relative to this reference extraction method, and presented as “expected genome copies per ml”.

211 As determined by reference extraction of aliquots of GBS cells suspension in PBS (using combined 212 bead-beating, ACH treatment and MagNA Pure extraction) there were $1.84 \times 10^{7}\left(95 \%\right.$ CI $4.4 \times 10^{6}-$ $\left.2132.3 \times 10^{7}\right)$ genome copies per ml of high spike EDTA blood and $1.68 \times 10^{4}\left(95 \%\right.$ CI $9.8 \times 10^{3}-2.1 \times$ 
$10^{4}$ ) genome copies per $\mathrm{mL}$ of low spike blood. Expected copies per PCR reaction $(3 \mu \mathrm{l}$ aliquot from a $215100 \mu \mathrm{l}$ or $200 \mu \mathrm{l}$ DNA extract) varied from $9.4 \times 10^{3}$ to $1.7 \times 10^{5}$ copies in the case of high spike 216 samples, and 9 to 152 copies in the case of low spike samples, depending on the dilution factor 217 involved in pre-lysis and extraction (Table S1).

\section{Comparison of different pre-lysis and extraction protocols.}

Figure 1 summarises the differences in absolute yield of gDNA in the high-spike experiments, according to extraction protocol. Table 2 shows percentage yield of each extraction, relative to the reference method, after taking into account the different dilution factors involved.

The overall effect of mechanical pre-lysis in the high spike samples was to increase yields of DNA by 51.3 fold (95\% CI; 31.6 - 85.1 fold, $\mathrm{p}<0.001)$ compared with no pre-treatment. Pre-lysis with ACH increased yields by 6.1 fold (95\% CI; $4.2-8.9$ fold, $\mathrm{p}<0.001)$. In preliminary experiments we found that $\mathrm{ACH}$ treatment is ineffective in undiluted whole blood, and that a 1 in 4 dilution prior to $\mathrm{ACH}$ treatment is optimal for maximal yield (data not shown). This introduces an unavoidable dilution step in the ACH pre-lysis protocol for whole blood, compared with mechanical lysis (Table S1). Treatment with ACH was slightly superior to mechanical lysis in terms of increased \% recovery of DNA (1.8 fold greater percentage recovery of DNA, $\mathrm{p}=0.020$ ) but because the $\mathrm{ACH}$ pre-lysis protocol required more sample dilution, the mechanical pre-lysis protocol gave higher overall higher yields of DNA.

There was no significant difference in DNA yield between the Qiagen and Fuji column-based extraction methods ( $\mathrm{p}=0.238$ ). The MagNA Pure extraction method gave the highest absolute yield of DNA, giving 1.96 fold greater yield than the column-based extraction methods (95\% CI; 1.26 to 3.07 fold, $\mathrm{p}=0.004)$. The SpeedXtract system preformed slightly less well. The spin-column based methods gave a yield 2.41 fold greater than the SpeedXtract kit (95\% CI; 0.74 to 4.31 fold, p=0.004), although the SpeedXtract protocol was the simplest, requiring only a magnetic rack. 


\section{Lower limits of detection}

In the "low spike" experiments we investigated the lower limits of detection for GBS in whole blood samples. Based on preliminary experiments the GBS load in these blood samples $\left(1.68 \times 10^{4}\right.$ genome copies. $\mathrm{mL}^{-1}$ ) was expected to be at or below the limits of detection using some extraction methods (data not shown). Due to the very low copy numbers expected, additional replicates were included in these experiments.

Firstly, results were compared based on pre-lysis method. In low spike samples without any pre-lysis, 8/25 (32\%) were positive for GBS DNA, with a mean genome copy number of 3.8 (95\% CI; 3.0 - 4.5) copies per reaction in positive samples. In samples with mechanical pre-lysis, 18/18 (100\%) were positive for GBS DNA, with a mean copy number of 58.1 (95\% CI; 42.2 - 74.0) copies per reaction. In samples with ACH pre-lysis, 16/34 (47\%) were positive for GBS, with a mean copy number of 19.6 (95\% CI; 5.3 - 33.8) copies per reaction. Of note, in the low-spike samples using the ACH pre-lysis protocol, 6/6 (100\%) replicates extracted using the SpeedXtract system were positive for GBS DNA. This compares to 5/10 (50\%) using Qiagen Blood Amp Mini kit, 2/10 (20\%) using the Fuji QuickGene and 3/8 (37.5\%) using MagNA Pure. As previously stated, ACH pre-lysis required a 1 in 4 dilution of whole blood. The chemistry of the Speed Xtract kit is different from the other kits; the supernatant containing most of the whole blood components is discarded early in the process following magnetic separation. It was not possible to incorporate mechanical pre-lysis into this protocol, but ACH could be used without an additional dilution step which may explain the superior performance.

Secondly, we compared the effects of extraction platform using samples without any pre-lysis (i.e. exactly according to manufacturer's protocol). GBS DNA was detected in: 3/6 (50\%) replicates extracted using the Qiagen Blood Mini Kit with a mean of 3.6 (95\% CI; 0.9 - 6.3) genome copies per reaction; 3/6 (50\%) replicates extracted with the Speed Xtract kit with a mean of 3.7 (95\% CI; 0.7 - 
6.7) genome copies per reaction; and 0/6 (0\%) replicates extracted with the Fuji Quickgene extraction platform. GBS DNA was detected in 2/7 (28.6\%) replicates where samples were extracted using the MagNA Pure system, with a mean of 4.1 (95\% CI; 3.3 - 4.9) genome copies per reaction.

\section{Discussion}

In this study, we found yields of $S$. agalactiae genomic DNA from blood, using several different commercial DNA extraction kits, were extremely low. Unsurprisingly, much higher yields were seen when kits were modified to include mechanical lysis, although the improvements using a very simple and rapid enzyme treatment were also impressive. To our knowledge, no previous studies have demonstrated use of $\mathrm{ACH}$ to improve lysis of $S$. agalactiae, or use of this enzyme at room temperature. We also used higher ACH unit activities than reported for other Gram-positive bacteria. Previous studies used arbitrary and varying amounts of ACH: 1000U/ml (18), 1500U/ml (15), 2000U/ml (16) or 4000U/ml (19). Using 4000U/ml, Niwa et al (19) reported complete lysis of a range of Gram-positive bacteria in $10-15$ minutes at $37^{\circ} \mathrm{C}$. Our method further increased the quantity of ACH (to $9625 \mathrm{U} / \mathrm{ml}$ ) in a simple, fast (5 minute) room temperature protocol. There may be scope to further improve yields by extending the incubation time, increasing the incubation temperature, or both.

Large differences in yield from the high-spike samples were seen between different extraction methods using the same pre-lysis protocol. With no pre-lysis, or using bead-beating, both the Quickgene and MagNA Pure methods consistently gave better performance than the Qiagen method. Using ACH prelysis, the yield for the Quickgene method was significantly reduced. The reasons for this are unclear. Comparing all 3 pre-lysis protocols, the MagNA Pure method was the most effective overall. This justified use of this method, with combined pre-lysis using both ACH and bead-beating, as the reference method for estimation of genome copy number in the spiked samples, and for yield calculations. The yields were lowest for extraction of the high-spike samples using the SpeedXtract method. However, the strong performance of this method for extraction of low-spike samples (due to 
295 the smaller dilution factors involved) should be emphasised. This method is attractive in practical 296 terms, and ACH pre-lysis did increase yield, so additional work to optimise this approach for GBS 297 testing may be worthwhile.

299 In terms of cost, the requirement for an automated extraction system (i.e. a MagNA Pure Compact or 300 MagNA Pure 96 instrument) makes the MagNA Pure method significantly more expensive overall 301 than the other methods. The reagent cost for MagNA Pure extractions was also the highest 302 (£5.46/sample), while the SpeedXtract method was the least expensive ( $£ 1.57 /$ sample). The reagents 303 for the Quickgene (£2.78/sample) and the Qiagen Blood Mini (£2.68/sample) and Qiagen UCP 304 (£3.34/sample) were intermediate in cost. The additional costs for pre-lysis were similar, at $£ 2.58 /$ sample for bead-beating and £2.46/sample for ACH. The overall extraction cost for the tested combinations with pre-lysis ranged from $£ 4.03$ to $£ 10.50$ per sample, excluding instrument costs. The optimum method in terms of both cost and performance was bead-beating with Quickgene extraction (£5.36/sample).

Conventional culture methods for detection of Group B streptococcus are time consuming, and can be unreliable. It has previously been shown that molecular methods can be used to detect GBS in culturenegative EDTA-blood samples, although at a low rate; 2/35 culture-negative blood samples of babies with probable sepsis were positive by PCR (2). As Qiagen Blood Mini kits were used to extract DNA from samples without any pre-lysis in that study, our results suggest that poor DNA recovery may have limited the sensitivity of PCR.

Recovering Gram-positive bacterial DNA from whole blood samples without a culture enrichment step remains a challenge. The utility of direct PCR in addition to culture to detect septicaemia and meningitis is well established for meningococcal septicaemia (12), and PCR may become the gold standard method for many other invasive bacterial infections, provided that optimised extraction methods are used. 
323 We found that processing samples with ACH or mechanical pre-lysis significantly increases the yield 324 of GBS DNA with a mean increase of 6.1 fold and 51.3 fold respectively, after allowing for different 325 dilution factors for different protocols. The ACH pre-lysis method is straightforward, amenable to 326 high-throughput or routine use, and the enzyme retains lytic activity for GBS for 30 days when stored 327 at $4^{\circ} \mathrm{C}$ (data not shown). Although more effective overall, and requiring no dilution step, the 328 mechanical pre-lysis protocol requires a bead beating instrument and involves more hands-on sample 329 preparation time.

There is growing clinical interest in the use of rapid molecular tests to detect GBS in late pregnancy, especially during labour, and in near-patient settings. Intrapartum screening of all pregnant women for GBS using rapid molecular methods was recommended following a European consensus conference in 2015 (20). However, sub-optimal recovery of GBS DNA from clinical specimens is a potentially important confounding factor that could affect the outcome of clinical trials in this area. A recent study in France (21) concluded that intrapartum PCR testing could improve diagnosis and prevention of GBS disease, compared to culture-based screening earlier in pregnancy. The study did not directly compare the analytical performance of PCR to intrapartum culture, although a separate French study in 339 a different hospital (22) reported the sensitivity of intrapartum GBS PCR, compared to broth enrichment culture, was 94.4\%. A Japanese study (23) concluded that intrapartum PCR testing for GBS was effective, although sensitivity was only $83.3 \%$ compared to broth enrichment culture on specimens collected at the same time.

344 Our data suggest that problems with DNA extraction efficiency could adversely affect the performance of molecular tests to detect GBS in clinical specimens, leading to underestimation of both analytical and clinical sensitivity, and systematic bias in clinical trials. Unless this issue is properly evaluated and addressed, these problems might limit the clinical utility of these potentially very important testing methods for rapid detection of GBS in intrapartum screening and diagnosis of neonatal infections. 


\section{Acknowledgements}

351

352 RB was funded by an Academic Research Fellowship (Queen’s University Belfast). This work was

353 supported by charitable funding from the McClay Foundation, Northern Ireland, U.K.

354

355 


\section{Legends}

358 Table1.

359 Sample pre-lysis and extraction methods evaluated in this study.

361 Table 2.

362 Yield of GBS genomic DNA from "high spike” saline and blood samples $\left(1.84 \times 10^{7}\right.$ genome 363 copies. $\left.\mathrm{ml}^{-1}\right)$.

364

365 Figure 1.

366 Box plot showing recovery of GBS genomic DNA from "high spike” saline and blood samples (1.84 x $36710^{7}$ genome copies. $\mathrm{ml}^{-1}$ ). A: reference extractions from PBS; B: blood extraction, no pre-lysis; C: 368 blood extraction, bead-beating pre-lysis; D: blood extraction, ACH pre-lysis. Abbreviations: nil = no 369 pre-lysis; $\mathrm{ACH}=$ pre-lysis with achromopeptidase; $\mathrm{BB}=$ bead-beating pre-lysis. 
372 1. Edmond KM, Kortsalioudaki C, Scott S, Schrag SJ, Zaidi AKM, Cousens S, Heath PT. 2012. Group B streptococcal disease in infants aged younger than 3 months: systematic review and meta-analysis. Lancet 379:547-556.

2. de Zoysa A, Edwards K, Gharbia S, Underwood A, Charlett A, Efstratiou A. 2012. Nonculture detection of Streptococcus agalactiae (Lancefield group B Streptococcus) in clinical samples by real-time PCR. Journal of Medical Microbiology 61:1086-1090.

3. van den Brand M, Peters RPH, Catsburg A, Rubenjan A, Broeke FJ, van den Dungen FAM, van Weissenbruch MM, van Furth AM, Kõressaar T, Remm M, Savelkoul PHM, Bos MP. 2014. Development of a multiplex real-time PCR assay for the rapid diagnosis of neonatal late onset sepsis. J. Microbiol. Methods 106:8-15.

4. Ke D, Ménard C, Picard FJ, Boissinot M, Ouellette M, Roy PH, Bergeron MG. 2000. Development of conventional and real-time PCR assays for the rapid detection of group B streptococci. Clinical Chemistry 46:324-331.

5. Wernecke M, Mullen C, Sharma V, Morrison J, Barry T, Maher M, Smith T. 2009. Evaluation of a novel real-time PCR test based on the ssrA gene for the identification of group

6. Morozumi M, Chiba N, Igarashi Y, Mitsuhashi N, Wajima T, Iwata S, Ubukata K. 2015. swabs from pregnant women. J. Infect. Chemother. 21:34-38. 
397 7. Bergseng H, Bevanger L, Rygg M, Bergh K. 2007. Real-time PCR targeting the sip gene for detection of group B Streptococcus colonization in pregnant women at delivery. Journal of Medical Microbiology 56:223-228.

8. Al-Soud WA, Rådström P. 2001. Purification and characterization of PCR-inhibitory components in blood cells. J. Clin. Microbiol. 39:485-493.

9. Mahalanabis M, Al-Muayad H, Kulinski MD, Altman D, Klapperich CM. 2009. Cell lysis and DNA extraction of gram-positive and gram-negative bacteria from whole blood in a disposable microfluidic chip. Lab Chip 9:2811.

10. Metwally L, Fairley DJ, Coyle PV, Hay RJ, Hedderwick S, McCloskey B, O'Neill HJ, 409 Webb CH, Elbaz W, McMullan R. 2008. Improving molecular detection of Candida DNA in whole blood: comparison of seven fungal DNA extraction protocols using real-time PCR. Journal of Medical Microbiology 57:296-303.

11. van Tongeren SP, Degener JE, Harmsen HJM. 2011. Comparison of three rapid and easy bacterial DNA extraction methods for use with quantitative real-time PCR. Eur. J. Clin. Microbiol. Infect. Dis. 30:1053-1061.

12. Bourke TW, McKenna JP, Coyle PV, Shields MD, Fairley DJ. 2015. Diagnostic accuracy of loop-mediated isothermal amplification as a near-patient test for meningococcal disease in

13. Bryant PA, Li HY, Zaia A, Griffith J, Hogg G, Curtis N, Carapetis JR. 2004. Prospective study of a real-time PCR that is highly sensitive, specific, and clinically useful for diagnosis of meningococcal disease in children. J. Clin. Microbiol. 42:2919-2925. 
425 14. Cruickshank R. Medical Microbiology: a guide to the laboratory diagnosis and control of infection, 11th ed. Livingstone, London.

15. Ezaki T, Suzuki S. 1982. Achromopeptidase for lysis of anaerobic gram-positive cocci. J. Clin. Microbiol. 16:844-846.

16. Slifkin M, Cumbie R. 1987. Serogrouping single colonies of beta-hemolytic streptococci with achromopeptidase extraction. J. Clin. Microbiol. 25:1555-1556.

17. Leonard RB, Carroll KC. 1997. Rapid lysis of gram-positive cocci for pulsed-field gel electrophoresis using achromopeptidase. Diagn. Mol. Pathol. 6:288-291.

18. Paule SM, Pasquariello AC, Hacek DM, Fisher AG, Thomson RB, Kaul KL, Peterson LR. 2004. Direct detection of Staphylococcus aureus from adult and neonate nasal swab specimens using real-time polymerase chain reaction. J Mol Diagn 6:191-196.

19. Niwa T, Kawamuraa Y, Katagiri Y, Ezaki T. 2005. Lytic enzyme, labiase for a broad range of Gram-positive bacteria and its application to analyze functional DNA/RNA. J Micro Methods

20. Di Renzo GC, Melin P, Berardi A, Blennow M, Carbonell-Estrany X, Donzelli GP, Hakansson S, Hod M, Hughes R, Kurtzer M, Poyart C, Shinwell E, Stray-Pedersen B, Wielgos M, El Helali N. 2015. Intrapartum GBS screening and antibiotic prophylaxis: a 
21. Raignoux J, Benard M, Huo Yung Kai S, Dicky O, Berrebi A, Bibet L, Chetouani AS, Marty N, Cavalie L, Casper C, Assouline-Azogui C. 2016. Is rapid intrapartum vaginal screening test of group B streptococci (GBS) during partum useful in identifying infants developing early-onset GBS sepsis in postpartum period? [Article in French] Arch Pediatr. 23:899-907

22. Defez M, Khizar F, Maurin M, Biot F, Pons JC, Sergent F. 2016. Usefulness of a rapid intrapartum real-time PCR assay in comparison with the group B Streptococcus culture screening at the end of pregnancy in pregnant women. [Article in French] J Gynecol Obstet Biol Reprod (Paris). S0368-2315(16)30057-6

23. Tanaka K, Iwashita M, Matsushima M, Wachi Y, Izawa T, Sakai K, Kobayashi Y. 2016. Intrapartum group B Streptococcus screening using real-time polymerase chain reaction in Japanese population. J Matern Fetal Neonatal Med. 29:130-4 


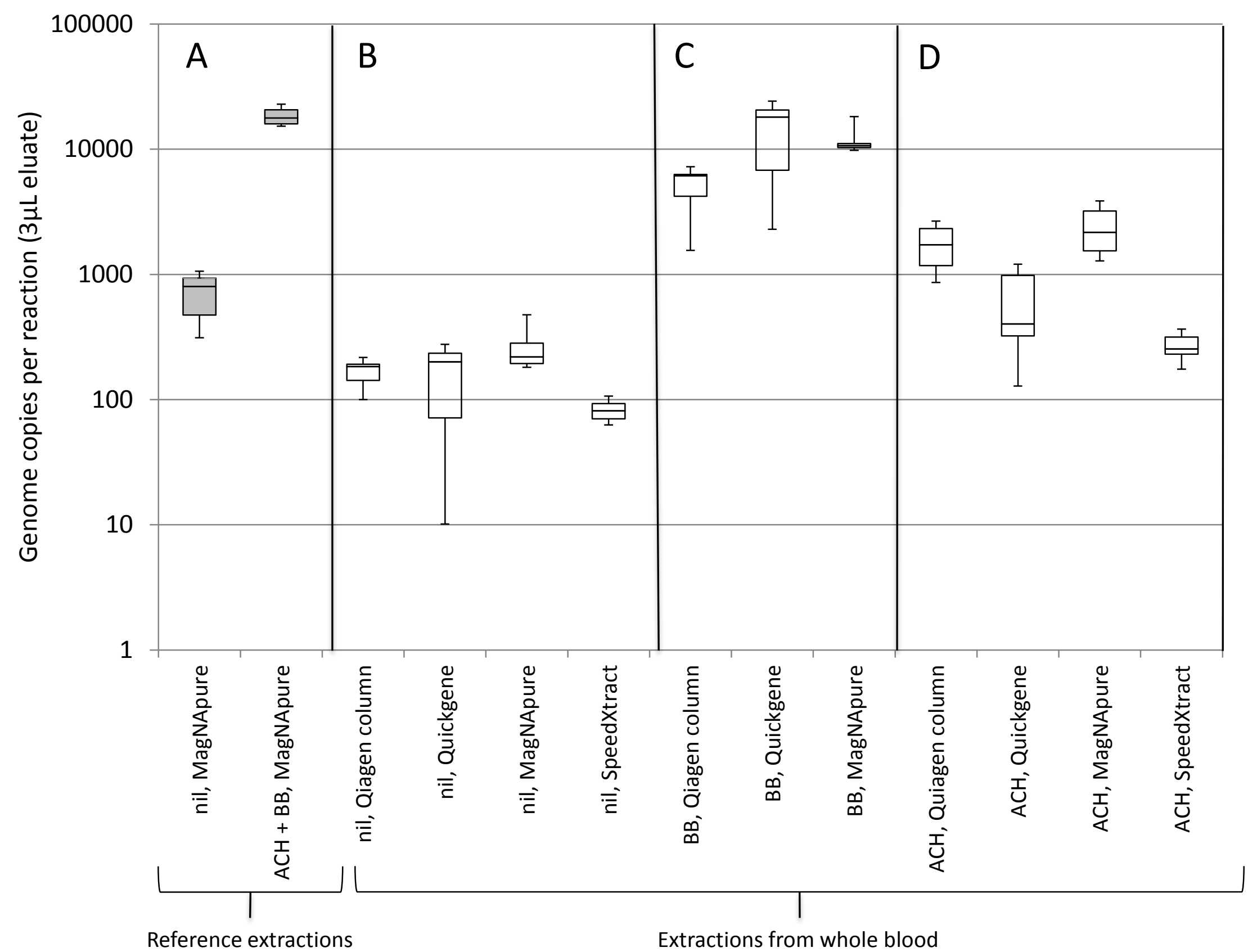

from saline 
Table1. Sample pre-lysis and extraction methods evaluated in this study

\begin{tabular}{ccccc}
\hline & $\begin{array}{c}\text { DNA extraction } \\
\text { kit }\end{array}$ & \multicolumn{3}{c}{ Pre-lysis method $^{\mathbf{1}}$} \\
\cline { 2 - 4 } & & None & ACH & $\begin{array}{c}\text { Bead- } \\
\text { beating }\end{array}$ \\
\cline { 2 - 4 } & $\begin{array}{c}\text { QIAamp Blood } \\
\text { Mini }\end{array}$ & + & + & - \\
\cline { 2 - 4 } & $\begin{array}{c}\text { QIAamp UPC } \\
\text { Pathogen Mini }\end{array}$ & - & - & + \\
\cline { 2 - 4 } & $\begin{array}{c}\text { QuickGene DNA } \\
\text { Whole Blood S }\end{array}$ & + & + & + \\
\hline $\begin{array}{c}\text { MagNA Pure } \\
\text { Compact }\end{array}$ & + & + & + \\
\hline SpeedXtract & + & + & -
\end{tabular}

${ }^{1}$ Some combinations could not be evaluated for technical reasons; see text for details. 
Table 2. Yield of GBS genomic DNA from "high spike” saline and blood samples (1.84 x $10^{7}$ genome copies. $\mathrm{ml}^{-1}$ ).

\begin{tabular}{lllll}
\hline Pre-lysis & Extraction & Expected & Mean copies detected & Yield \\
platform & copies per & per reaction $( \pm \mathrm{SE})$ & (\%) \\
& reaction & & \\
& &
\end{tabular}

\section{Saline:}

ACH \& bead- $\quad$ MagNApure

$5.53 \times 10^{4}$

$5.53 \times 10^{4}( \pm 9410)$

$100 \%$

beating*

None $\quad$ MagNApure $\quad 1.10 \times 10^{5} \quad 2160( \pm 929) \quad 1.95 \%$

EDTA-whole blood:

$\begin{array}{lllll}\text { None } & \text { QIAamp Blood Mini } & 1.10 \times 10^{5} & 503( \pm 132) & 0.46 \% \\ \text { None } & \text { QuickGene Mini-80 } & 1.10 \times 10^{5} & 480( \pm 332) & 0.43 \% \\ \text { None } & \text { MagNApure } & 5.53 \times 10^{4} & 792( \pm 336) & 1.43 \% \\ \text { None } & \text { SpeedXtract } & 5.53 \times 10^{4} & 247( \pm 50) & 0.45 \% \\ \text { Bead-beating } & \text { UCP Pathogen Mini } & 1.66 \times 10^{5} & 1.55 \times 10^{4}( \pm 6410) & 9.34 \% \\ \text { Bead-beating } & \text { QuickGene Mini-80 } & 5.53 \times 10^{4} & 4.35 \times 10^{4}\left( \pm 2.79 \times 10^{4}\right) & 26.2 \% \\ \text { Bead-beating } & \text { MagNApure } & 1.10 \times 10^{5} & 3.54 \times 10^{4}( \pm 9570) & 32.0 \% \\ \text { ACH } & \text { QIAamp Blood Mini } & 1.38 \times 10^{4} & 5240( \pm 1978) & 37.9 \% \\ \text { ACH } & \text { QuickGene Mini-80 } & 1.38 \times 10^{4} & 1800( \pm 1390) & 13.1 \% \\ \text { ACH } & \text { MagNApure } & 9400 & 7190( \pm 3220) & 76.4 \% \\ \text { ACH } & \text { SpeedXtract } & 5.53 \times 10^{4} & 804( \pm 211) & 1.45 \%\end{array}$

* Reference extraction 